2010:59:1 Activity Promotion for Community Dwelling Older People: A Survey of the Contribution, of Primary Care Nurses

Activity promotion for community dwelling older people: a survey of the contribution, of primary care nurses

\title{
Claire Goodman*
}

Susan L Davies*

Susie Dinan+

Sharon See Tai+

Steve Iliffe +

*Centre for Research in Primary and Community Care University of Hertfordshire

AL10 9AB

+Primary Care and Population Sciences University College London 
2010:59:1 Activity Promotion for Community Dwelling Older People: A Survey of the Contribution, of Primary Care Nurses

\title{
Activity promotion for community dwelling older people: a survey of the contribution, of primary care nurses
}

\begin{abstract}
Study aims: To discover the current level of nurse led involvement in activity promotion for older people in primary care and to explore the knowledge and attitudes of primary care nurses about health benefits of activity promotion for older people.

Background: The importance of improving and maintaining activity levels in later life is well established. However, intervention studies show that the uptake of and adherence to physical activity programmes by older people are highly variable. The optimal approach to activity promotion for older people is not well understood. Although many activity promotion schemes and evaluations assume that specialist exercise trainers are needed, it remains unclear who is best placed to facilitate activity promotion for older people, and if this is something in which existing primary care practitioners (specifically nurses) could and should take a leading role.

Methods: This study surveyed all nurses and health visitors working in five primary care organisations in an inner city area. A semi structured postal questionnaire asked about their knowledge and attitudes to the benefits of exercise in later life, their current levels of involvement in promoting physical activity with older people, and their personal activity levels.
\end{abstract}


2010:59:1 Activity Promotion for Community Dwelling Older People: A Survey of the Contribution, of Primary Care Nurses

Findings: The overall response rate was $54 \%(n=521)$. The responses of 391 district nurses and practice nurses' are presented here. Nurses had the commitment and (depending on the focus of their work) different opportunities to promote physical activity with older patients. There were organisational and individual constraints on their ability to be involved in this aspect of health promotion work themselves, or to refer older people to local activity promotion schemes. Nurses did not have a structured approach when promoting physical activity with older people and had only a partial awareness of the limitations of their knowledge or skills when promoting activity with older people.

Conclusions: For promotion of physical activity by older people to be meaningfully incorporated into primary care nursing work there is a need to develop a more strategic approach that can optimise the opportunities and interest of primary care nurses and develop the knowledge and skills of the workforce in this area of nursing work.

\section{What is already known}

Regular physical activity, including muscle strengthening and aerobic activity is essential for healthy ageing.

Nurses based in primary care settings are well placed to support older people to engage in regular physical activity but little is known about what kind of support they offer this population and their existing level of involvement, knowledge and training in this area of health promotion work.

\section{What this study adds}

Nurses recognise activity promotion as part of their role in working with older people and were able to provide examples of how they encouraged increased physical activity. 
2010:59:1 Activity Promotion for Community Dwelling Older People: A Survey of the Contribution, of Primary Care Nurses

The organisational constraints, absence of specific training, variable knowledge and the unplanned approach to this area of work suggest that nurses working in primary care are currently ill equipped to enable older people to increase and maintain their levels of physical activity and function.

This study demonstrates a need for a more strategic approach to the development of public health and physical activity initiatives for older people that can optimise the contribution of individual nurses in this area of health promotion.

Key words Activity promotion, district nursing, practice nursing, older people, primary care. 
2010:59:1 Activity Promotion for Community Dwelling Older People: A Survey of the Contribution, of Primary Care Nurses

\section{INTRODUCTION}

For older people, the benefits of participating in regular physical activity include maintaining bone density, reducing the risk of fractures, falls, improving mood, lowering blood pressure, achieving a level of functional capacity associated with people 10-15 years younger with some longitudinal studies suggesting physical activity is linked to a reduced risk of developing dementia (e.g. Gillespie et al 2003, Fransen et al 2003, Bonaiuti et al 2003, Hillsden et al 2005, Vogel et al 2009, Windle et al 2010). Despite this evidence of benefit, the uptake and involvement in regular activity by older people is relatively low and declines with age (, Crombie et al 2004 Paivi et al 2010). Community nurses are well placed as health care professionals to provide physical activity advice to older people. However, little is known about how they engage in this kind of health promotion work, what they recommend and the kind of training and support they require (Douglas et al 2006, Laws et al 2008). This paper reports on a survey of nurses working with community dwelling older people about the opportunities they had to encourage older peoples' participation in physical activity and the knowledge and training that informed their work.

\section{Background}

Although older people may reach higher levels of activity than younger age groups (Fisher et al, 2002), the majority do not achieve levels necessary to improve either their cardiovascular fitness and or their psychological health (Nelson et al, 2007). Evidence suggests that there is a progressive reduction in physical activities with advancing age and this is more marked for members of ethnic minorities and those on low incomes (Crombie et al 2004, Riebe et al 2005). Older people are recommended to have at least 30 minutes moderate intensity physical activity on at least five days a week as well as participate in activities that promote 
2010:59:1 Activity Promotion for Community Dwelling Older People: A Survey of the Contribution, of Primary Care Nurses

strength, co-ordination, and balance (Department of Health DoH, 2004, Nelson et al 2007).

Older people are more likely to achieve and sustain recommended levels of physical activity if a mix of behavioural and cognitive approaches to activity promotion is used, (Lawlor et al 2001, Thurston and Green 2004, Stathi et al 2004, Hillsden et al 2002, 2005). This approach can be done using exercise therapists working in primary care settings, even with frail older people (Young and Dinan 2005, Dinan et al 2006). There is also some evidence that primary care physicians can increase physical activity in their patients, at least for a short period, by giving simple advice and self-monitoring equipment like pedometers and exercise diaries (Steptoe, 1999, Hillsden et al, 2004Aittasalo et al 2006, Williams et al 2007). Less is known however about how nurses working in primary care integrate this aspect of health promotion work in to their everyday practice.

\section{The nursing role in activity promotion}

Primary care nurses trained in behavioural approaches have been shown to exert a positive influence on their patient's healthy behaviours including, increasing their self reported physical activity levels. Older people who recalled being given activity advice given by health care professionals or who received structured input were more likely to start participating in exercise classes than those who did not recall having received such advice

(Hivensalo et al, 2003 Kerse et al 2005). Few studies have explored what nurses are doing in terms of activity promotion as part of their everyday work, although some suggest a

relationship between personal beliefs and or willingness to engage with physical activity and health promotion (McKenna et al 1998, Laws et al 2008, 2009). There is a lack of research evidence around primary care nurses' involvement in health promotion or public health initiatives to increase physical activity e.g. for the prevention of falls, and some evidence to suggest that primary care practitioners lack confidence in this type of activity promotion 
2010:59:1 Activity Promotion for Community Dwelling Older People: A Survey of the Contribution, of Primary Care Nurses

(Iliffe et al, 1996, Graham et al, 2005 Douglas et al 2006, McHugh et al 2009). Any future interventions that involves primary care nurses as the lead or support for promoting physical activity with community dwelling older people needs to take into account their current levels of knowledge and practice in this area .

This paper describes a study which investigated the feasibility of involving primary care nurses in activity promotion for older people, in terms of their capacity, contact with this client group, training in activity promotion, and personal interest.

The term "physical activity" denotes those activities that are intended to promote health and well-being that are of sufficient duration, intensity, and frequency to help reduce the risk of ill health that can arise from decreased mobility in older people (Caspersen, Powell, \& Christensen, 1985). The study questions were:

1. What is the current level of nurse led involvement in activity promotion for older people in primary care?

2. What are the knowledge and attitudes of primary care nurses about health benefits of activity promotion for older people? 
2010:59:1 Activity Promotion for Community Dwelling Older People: A Survey of the Contribution, of Primary Care Nurses

\section{METHODS}

A survey design was used to develop and mail out a semi structured questionnaire on community nurses' experience of and involvement in encouraging older people to engage in physical activity.

\section{Participants}

The focus of the study was on nurses working in primary care. Nurses working in primary care within the boundaries of the five primary care trusts (PCTs) were identified and invited to participate in the study by the Clinical Service Managers or the Practice Development Nurses of each participating PCT. They included Practice Nurses (employed by general practitioners), district nurses (home care nurses) and Health Visitors (Public Health Nurses).

The questionnaire was posted out to all primary care nurses in each of the five PCTs $(n=971)$. As the focus was on older people and mainstream nursing services, excluded from the survey were clinical nurse specialists working with particular patient groups e.g. palliative care nurses, continence nurses and mental health nurses. Nurses and Health Visitors who worked the equivalent of two days or less, or who had no contact with older people were asked only to complete questions on their speciality, hours worked, consultation times, and caseload

\section{Data Collection}

Following a review of the literature and iterative discussions with the research team and academics and practitioners interested in activity promotion strategies for older people a structured five-page questionnaire was piloted with a convenience sample of practice nurses and district nurses who were not working in the proposed study sites $(\mathrm{n}=10)$. Following minor amendments for clarity, the questionnaire was divided into four main areas:

1) Current involvement in promoting activity with older people and awareness of local initiatives available for older people, 
2010:59:1 Activity Promotion for Community Dwelling Older People: A Survey of the Contribution, of Primary Care Nurses

2) Training in and knowledge of activity promotion methods,

3) Attitudes towards activity promotion for older people,

4) Personal activity levels and demographic information.

There were 20 closed questions; the majority required a tick box response from a choice of possible answers that either asked the respondent for factual information or strength of agreement with statements about their knowledge, experience and aspirations when promoting activity with older people. At the end of the questionnaire there was an open question inviting comments and observations about nursing involvement in this area of work. Questionnaires were sent out through the nurses' NHS organisation with a stamped addressed envelope for return, with two reminders posted to non-responders at two-week intervals.

\section{Ethics}

The local National Health Service (NHS) research ethics committee received and approved the study. Potential participants were provided with written information about the study and written consent was obtained with the returned postal questionnaires. All responses were confidential and data was anonymised once recruitment was complete.

\section{Analysis}

Questionnaire data was organised according to the questions asked and analysed descriptively using SPSS v 12.0 for Windows (SPSS Inc., Chicago USA) to characterise the sample in terms of demography, attitudes towards activity promotion for older people, training, current practice, awareness of schemes, knowledge and personal activity. Free text responses were explored using content analysis. 
2010:59:1 Activity Promotion for Community Dwelling Older People: A Survey of the Contribution, of Primary Care Nurses

\section{FINDINGS}

The overall response rate was $54 \%(n=521)$ of which 515 had been completed and were entered into SPSS for analysis. Practice Nurses has the highest response rate of the three nursing groups (see table 1). Only two health visitors had regular contact with older people as part of their everyday work, therefore the analysis included in this paper focuses on the responses of the 391 District and Practice nurses.

Insert table 1 here

\section{Opportunities for health promotion}

Nurses were asked if they had the time and opportunity to discuss activity promotion with older people, they were asked to state how long they usually spent with individual patients/clients and what proportion of their work involved contact with older people. Although older people are the highest users of health services just over half of ( $53 \% \mathrm{n}=118)$ of Practice Nurses' said that less than $35 \%$ of their patients were aged 65 years and older. In contrast, and unsurprisingly, the majority of District Nurses' (70\% 110) patients were 65 years or older. Twenty eight per cent (44) of District Nurses reported spending 30 minutes or more with their patients; but 60\% (126) of Practice Nurses' whose work is clinic based spent half that time or less.

\section{Activity promotion knowledge and practice}

There were two main ways in which nurses encouraged older people to increase their physical activity; through assessment and advice, and through referral to other activity 
2010:59:1 Activity Promotion for Community Dwelling Older People: A Survey of the Contribution, of Primary Care Nurses

promoting services. The majority $(79 \%, \mathrm{n}=359)$ of district nurses and practice nurses stated that they discussed specific ways of increasing activity levels with their older clients. Nurses who reported on the type of advice and support offered in the preceding 6 months indicated that they reviewed activity levels, and provided advice on increasing stamina and the benefits of brisk walking. There was also some evidence of nurses referring older people to specialist exercise groups and falls clinic, or providing targeted advice likely to encourage patients to do five sessions a week of moderate intensity activity . The most common types of activity advice (chosen from the list of possible options) were: review of physical activity levels, methods of increasing stamina, brisk walking, and chair-based exercises (See table 2).

The majority of District Nurses ( $\mathrm{n}=106,69 \%$ out of 153 who responded) and Practice Nurses $(\mathrm{n}=122,66 \%$ out of 185 who responded) could identify local activity promotion initiatives suitable for older people. Of those who made referrals, these were more likely to be activities that promoted general physical health (swimming ( $\mathrm{n}=148,29 \%$ of nurses), walking groups $(\mathrm{n}=127,25 \%)$, rather than those designed to address specific health related issues (specialist falls prevention services ( $n=6312 \%)$, or exercise groups for people with osteoporosis $(n=26$ $5 \%)$.

\section{Insert table two here}

\section{Confidence in promoting activity with older people}

A series of questions asked the nurses about their, confidence in and knowledge about providing different types of advice about physical activity to older people, and about making referral decisions Nurses were asked to make a judgement from a list of physical attributes (strength, flexibility, co-ordination, endurance) as to which one was most important for maintaining function in ageing. Only $16 \%(\mathrm{n}=52)$ selected the correct answer (strength), but 
2010:59:1 Activity Promotion for Community Dwelling Older People: A Survey of the Contribution, of Primary Care Nurses

only $10 \%(\mathrm{n}=31)$ indicated that they were unsure of the answer. To assess nurses 'confidence and knowledge when providing advices to older people with different health needs, participants were asked to choose from a range of activities (e.g. swimming, tai chi, circuit training) and indicate which may be appropriate for older people who were sedentary, had stable angina or were recovering from a stroke but had residual weakness. Nurses could indicate where they were unsure. Overall responses to this set of questions were lower than those that asked about their views about activity promotion and its value. Respondents were confident in how to advise older people who were sedentary with no particular health problems but not the other client groups.

\section{Attitudes towards activity promotion, education and training}

A series of statements explored whether primary care nurses agreed that they should be more involved in activity promotion. Despite the strong endorsement of activity promotion as part of the nurses' role, participants also emphasised the lack of time they had to give to this work, which was compounded by their lack of training, staff shortages and organisational constraints. The majority $(n=349,89 \%)$ indicated that they strongly/ agreed that $\mathrm{t}$ nurses should be more involved in promoting activity for older people. However, only just over half of the respondents $(n=202,52 \%)$ thought that older people responded well to advice on how to increase their activity levels and agreed that it was difficult to make time for this type of work $88 \%(n=345)$. Factors that inhibited this kind of health promotion work were, lack of information on what is available for older patients and referral problems within the organisation, limited access to appropriate schemes including problems getting transport for older patients to attend groups, individual patients' physical condition and intermittent contact with this age group. 
2010:59:1 Activity Promotion for Community Dwelling Older People: A Survey of the Contribution, of Primary Care Nurses

Seventy two (14\%) of the nurses in the survey had received training in activity promotion but only eight had obtained a formal qualification on an activity related course. Over half did not believe they had appropriate training to provide advice on physical activity to older people $(58 \%(\mathrm{n}=225)$.

\section{Participants' personal levels of activity}

Just over half $(55 \%, \mathrm{n}=216)$ of the nurses described themselves as participating in regular exercise with $46 \%(n=181)$ exercising weekly. This compares favourably with the view that only $31 \%$ of adults achieve a high enough level of physical activity to reap health benefits (DH, 2004). However, for a large number of those exercising regularly, 30\% ( $n=107)$ identified activities could be incorporated in to their everyday life, e.g. walking to work. Lower numbers of nurses were participating in planned structured activity such as cycling $(\mathrm{n}=37,7 \%)$, gym $(\mathrm{n}=76,15 \%)$, jogging $(\mathrm{n}=38,7 \%)$ and swimming $(\mathrm{n}=93,18 \%)$, activities that are possibly more likely to be of sufficient duration, intensity, and frequency to improve fitness and health. Unlike previous studies however, personal levels of activity however were not significantly associated with influence nurses' willingness to engage with providing advice on activity to older people.

\section{DISCUSSION}

Within primary care the importance of the nurse as an enabler and facilitator of good health with older people and populations living with long term conditions is well established.

(Goodman et al, 2010). Nelson et al (2007) in their review of the evidence concluded that the breadth and strength of the evidence means that physical activity should be one of the highest priorities for prevention and treating disease and disablement in older adults. 
2010:59:1 Activity Promotion for Community Dwelling Older People: A Survey of the Contribution, of Primary Care Nurses

Initiatives that aim to increase physical activity amongst older people can be placed along a continuum from approaches that support personal choice, to those that recognise that choices about activities are influenced by access to facilities and the physical environments and policies (King et al 2002).. Interventions that involve nurses need to consider what kind of nurse is best placed to provide what kind of support (Markle-Reid et al 2006). This study found that district nurses and to a lesser extent practice nurses have the contact, opportunity and interest to be part of that implementation. However, when promoting physical activity with older people many nurses were not aware of the limitations of their knowledge or skills.

In England and Wales, one in four people over the age of 75, and one in two of those aged over 85, will receive care from a district nurse (Queens Nursing Institute 2006). District nurses have the potential to provide support and review to older people with complex and long term conditions in their home Practice nurses too, can provide clinic based interventions (Iliffe et al 1996) and. However, it is unlikely that nurses will develop skills that reflect how and where they work, without formal partnerships with other professionals (e.g. exercise therapists), access to resources, known referral methods, and onward links to other physical activity programmes (Carnegie Research Institute 2007).

The findings from this survey echo other international studies on the competencies and opportunities primary care nurses have to participate in health promotion work in general. (for example Irvine et al 2005 Robinson et al 2006, Laws 2008, 2009, Johansson et al 2009). For many, organisational constraints such as access to training and other work commitments limited their ability to prioritise this kind of work with older people. 
2010:59:1 Activity Promotion for Community Dwelling Older People: A Survey of the Contribution, of Primary Care Nurses

A significant proportion of the participants were uncertain as to whether older people responded well to initiatives to help them increase their physical activities. A concern validated by studies that suggest conventional approaches to promoting and sustaining physical activity with older people may not be effective and that this population may prefer programmes tailored to their particular needs in their homes or local community centres (Iliffe et al 2010). Findings suggested that of the interventions available in the study area, several were inaccessible to older people and this limited nurses' referral choices. Survey responses also indicated that nurses had difficulty specifying what kind of activity would be appropriate for different groups of older people. Practitioners need to be confident that initiatives and guidance to support increased physical activity are suitable for older patients, particularly for those with several long term conditions including dementia (Skelton and Dinan 2007, see also. resources provided by British Heart Foundation Active for Life www.bhfactive.org.uk/older-adults/index.html).

\section{Limitations of the study:}

There were almost as many nurses who did not respond to the survey as did. Although the overall response rate to the survey questionnaire compares favourably with equivalent studies undertaken with corresponding groups of primary care nurses (Evans et a 2005, Douglas et al 2006 ) it is likely that those who responded had a greater interest in activity promotion for older people than those who did not. The exclusion of specialist community nurses working with particular older patient groups may mean that the involvement of nurses in promoting physical activity has been under-reported in this survey. 
2010:59:1 Activity Promotion for Community Dwelling Older People: A Survey of the Contribution, of Primary Care Nurses

The survey was undertaken in a high population density, inner city environment.

Nevertheless, in terms of their demographic profile the respondents in this survey reflected the characteristics of the general population of community nurses within England and the findings complement those of a Scottish based study (Douglas et al 2006). It is however, likely that patterns of working, access to specialist services and training provision would differ from those in more suburban or rural areas.

\section{Conclusions}

Physical activity levels are low in the older population and intervention research so far has demonstrated only modest, short-term improvements in activity levels (Iliffe et al 2010). It is possible that contextual factors, recognised by the nurses in this survey shape the opportunities older people have to engage in and sustain ongoing physical activity (Goodman et al 2007). . For primary care nurse led activity promotion for older people to become a part of routine care, further work is needed to equip and enable the workforce to tailor the advice they provide to older people and develop strategies that monitor its effectiveness for older people, both in the long and short term.

Words excluding 3142 excluding abstract and references

\section{References}

Aittasalo, M., S. Miilunpalo, et al. (2006). A randomized intervention of physical activity promotion and patient self-monitoring in primary health care Preventive Medicine 42(1): 4046. 
2010:59:1 Activity Promotion for Community Dwelling Older People: A Survey of the Contribution, of Primary Care Nurses

Bonaiuti D, Shea B, Iovine R, Negrini S, Robinson V, Kemper HC, Wells G, Tugwell P, Cranney A. . (2003) Exercise for preventing and treating osteoporosis in postmenopausal women. Cochrane Databast Systematic Reviews; (3): Systematic Reviews. ; (1): CD004017

British Heart Foundation Active for Later Life Resource. www.bhfactive.org.uk/olderadults/index.html (accessed 17.11.10)

Carnegie Research Institute (2007) The National Evaluation of LEAP (Local Exercise Action Pilots ) report prepared for the Department of Health Leeds Metropolitan University Leeds

Caspersen CJ, Powell KE, Christensen GM. (1985). Physical activity, exercise, and physical fitness: Definitions and distinctions for health-related research. Public Health Reports, 100,126-131.

Crombie, I.K., Irvine L., Williams B., McGinnis A.R., Slane P.W., Alder E.M.and McMurdo, M.E.T. (2004)Why Older People do not participate in leisure time physical activity: a survey of activity levels, beliefs and deterrents. Age and Ageing,33, 287-292.

Department of Health (2004) Choosing Health London Department of Health,

Dinan, S. Lenihan P, Tenn, T. Iliffe S. (2006) Is the promotion of physical activity in vulnerable older people feasible and effective in general practice? Br J Gen Pract. 1; 56(531): 791-793.

Douglas, F; van Teijlingen, E; Torrance,N.; Fearn, P, Kerr, A.; Meloni, S (2006) Promoting physical activity in primary care settings: health visitors' and practice nurses' views and experiences Journal of Advanced Nursing Volume 55, Number 2, 159-168

Evans C; Drennan V; Roberts R (2005). Practice nurses and older people: a case management approach to care. Journal of Advanced Nursing 51 (4): 343-352 
2010:59:1 Activity Promotion for Community Dwelling Older People: A Survey of the Contribution, of Primary Care Nurses

Fisher K. (2002) Chewing the Fat: the story time diearies tell about physical activity in the United Kingdom Institute for Social and Economic Research Working Paper number 200213 University of Essex

Fransen M, McConnell S, Bell M (2003) Exercise for osteoarthritis of the hip or knee. Cochrane Database Systematic Reviews.( 3):CD004286.

Gillespie, LD, Gillespie, WJ, Robertson, MC, Lamb, SE, Cumming, RG, Rowe, BH. (2003) Interventions for preventing falls in elderly people. Cochrane Database Systematic Reviews.( 3):CD000340.

Goodman C. . Davies S. See Tai S. and Dinan S. Iliffe S (2007) Promoting older peoples' participation in activity, whose responsibility? A case study of the response of health, local government and voluntary organisations Journal of Interprofessional Care 21 (5) 515-528

\section{Goodman,C. ,Drennan,V.,Davies,S.,Masey,H.,Gage, H.,Manthorpe,J.}

Brierley,S.,Scott,C. And Iliffe S. (2010) Nurses as Case Managers in Primary Care: the Contribution to Chronic Disease Management Report for the National Institute for Health Research Service Delivery and Organisation programme SDO Project (08/1605/122)

Graham, R.; Dugdill, L.; Cable, N. 2005 Health professionals' perspectives in exercise referral: implications for the referral processErgonomics, 48, 11-14:1411-1422

Hillsdon, M., Thorogood, M., White, I and Foster, C. (2002). Advising People to take more exercise is ineffective: a randomised controlled trial of physical activity promotion in primary care. International Journal of Epidemiology:31:808-15

Hillsdon, M., Thorogood, M., White, I and Foster, C. (2002). Advising People to take more exercise is ineffective: a randomised controlled trial of physical activity promotion in primary care. International Journal of Epidemiology:31:808-15 
2010:59:1 Activity Promotion for Community Dwelling Older People: A Survey of the Contribution, of Primary Care Nurses

Hillsdon M. Foster C. Naidoo B., Crombie H. (2005) $2^{\text {nd }}$ edition The effectiveness of public health interventions for increasing physical activity among adults: a review of reviews. Health Development Agency, London February

Hirvensalo, M., E. Heikkinen, et al. (2003)"The effect of advice by health care professionals on increasing physical activity of older people Scandinavian Journal of Medicine \& Science in Sports 13 (4): 231-236

Iliffe S, Smith P, Gould MM \& See Tai S (1996) Exercise as therapy: results from group interviews of practices involved in an inner London prescription for exercise scheme Health Education Journal 1996: 55; 439-446

Iliffe, S., Kendrick, D., Morris, R., Skelton, D., Gage, H., Dinan, S., Stevens, Z., Pearl,

M. \& Masud, T. (2010) Multi-centre cluster randomised trial comparing a community group exercise programme with home based exercise with usual care for people aged 65 and over in primary care: protocol of the ProAct $65+$ trial. Trials, 11(1), 6.

Irvine F. (2005) Exploring district nursing competencies in health promotion: the use of the Delphi technique. J Clin Nurs. 14:965-975.

Johansson H, Weinehall L, Emmelin M (2009) "It depends on what you mean": a qualitative study of Swedish healthg professionals' views on health and health promotion. BMC Health Serv Res.;9:191. doi: 10.1186/1472-6963-9-191

Kerse, N., Elley, C R, Robinson,E., Arroll, B. (2005) Is Physical Activity Counseling Effective for Older People? A Cluster Randomized, Controlled Trial in Primary Care Journal of the American Geriatrics Society 53:11 1951 
2010:59:1 Activity Promotion for Community Dwelling Older People: A Survey of the Contribution, of Primary Care Nurses

King, A., Stokols, D., Talen, E., Brassington, G S, Killingsworth, R. (2002) Theoretical approaches to the promotion of physical activity. Forging a transdisciplinary paradigm American Journal of Preventive Medicine:23, 2, Supplement 1, 15-25

$\underline{\text { Lawlor DA, Hanratty B }}$ (2001) The effect of physical activity advice given in routine primary care consultations: a systematic review. Journal of Public Health Medicine.; 23(3):219-26

Laws, R., S. Kirby, et al. (2008). "'Should I and Can I?": A mixed methods study of clinician beliefs and attitudes in the management of lifestyle risk factors in primary health care." BMC Health Services Research 8(1): 44.

Laws, R., L. Kemp, et al. (2009). "An exploration of how clinician attitudes and beliefs influence the implementation of lifestyle risk factor management in primary healthcare: a grounded theory study." Implementation Science 4(1): 66.

Markle-Reid, M., Browne, G., Weir, R., Gafni, A., Roberts, J. \& Henderson, S.R. (2006)

The Effectiveness and Efficiency of Home-Based Nursing Health Promotion for Older People: A Review of the Literature. Medical Care Research and Review, 63(5), 531-569.

McHugh G.A.,Horne,M.,Chalmers,K.I. Luker,K.A. (2009) Specialist Community Nurses: a critical analysis of their role in the management of long term conditions Int $J$ Environ.Res.Public Health 6 2550-2567

Mckenna J, Naylor PJ and N. McDowell (1998) Barriers to physical activity promotion by general practitioners and practice nurses British Journal of Sports Medicine 32: 242-247.

Nelson,M.E, Rejeski,W.J.,Blair,S.N.,Duncan,P.W., Judge,J.O.,King,A.C.,Macera,C.A. and Casteneda-Sceppa,C. (2007). "Physical Activity and Public Health in Older Adults: Recommendation From the American College of Sports Medicine and the American Heart Association10.1161/CIRCULATIONAHA.107.185650." Circulation 116(9): 1094-1105. 
2010:59:1 Activity Promotion for Community Dwelling Older People: A Survey of the Contribution, of Primary Care Nurses

Päivi ,M. Hirvensalo M., Terttu,P (2010) Changes in Physical Activity Involvement and Attitude toPhysical Activity in a 16-Year Follow-Up Study among the Elderly Journal of Aging Research online access doi:10.4061/2010/174290

Queens Nursing Institute (2006) 2020 Vision focusing on the impact of district nursing Queens Nursing Institute London www.qni.org.uk

Riebe, D, Garbe,r CE, Rossi, JS, Greaney, ML, Nigg, CR, Lees, FD, Burbank, PM,

Clark, P.G. (2005) Physical activity, physical function, and stages of change in older adults. American Journal of Health Behavior; 29(1):70-80.

Robinson KL, Driedger MS, Elliott SJ, Eyles J. (2006) Understanding facilitators of and barriers to health promotion practice. Health Promot Pract.2006;7:467-476.

Skelton,D and Dinan, S (2007) Explaining about... the benefits of active ageing Working with Older People 11 I 4 10-15

Steptoe, A., S. Doherty, et al. (1999). "Behavioural counselling in general practice for the promotion of healthy behaviour among adults at increased risk of coronary heart disease: randomised trial BMJ 319943-948.

Stathi A, McKenna J, Fox KR (2004) The experiences of older people participating in exercise referral schemes. Journal Royal Society of Health.:124(1):18-23.

Thurston M, Green K (2004) Adherence to exercise in later life: how can exercise on prescription programmes be made more effective? Health Promotion International:Sep;19(3):379-87

Williams NH, Hendry M, France B, et al. (2007) Effectiveness of exercise referral schemes to promote physical activity in adults: systematic review. Br J Gen Pract.;57(545):979-986

Windle G, Hughes D, Linck P, Russell I, Woods B. (2010) Is exercise effective in promoting mental well-being in older age? A systematic review.Aging Ment Health. (6):65269. 
2010:59:1 Activity Promotion for Community Dwelling Older People: A Survey of the Contribution, of Primary Care Nurses

Vogel, T., Brechat, P.H., Leprêtre, P.M., Kaltenbach, G., Berthel, M. \& Lonsdorfer, J.

(2009) Health benefits of physical activity in older patients: a review. International Journal of Clinical Practice, 63(2), 303-320.

Young A. and Dinan S. (2005) Activity in later life. British Medical Journal.; 330:189-91.

Table 1 Questionnaires received according to speciality

\begin{tabular}{|l|l|}
\hline Speciality $\mathrm{n}=515$ & Number received (\% of total received) \\
\hline District nurses & $169(33 \%)$ \\
\hline Practice nurses & $\mathbf{2 2 2}(43 \%)$ \\
\hline Health visitors & $112(22 \%)$ \\
\hline Other specialities & $12(2 \%)$ \\
\hline
\end{tabular}

NB Of the 112 Health Visitors who took part in the survey, only 2 worked specifically with older people; hence from sections 1 to 4 analysis includes the whole group, with section 5 onwards focusing on District Nurses and Practice Nurses only. (Responses varied across the survey as a consequence of missing data, so response size, $n$ is given for each variable.) 
2010:59:1 Activity Promotion for Community Dwelling Older People: A Survey of the Contribution, of Primary Care Nurses

Table 2 Most common types of activity advice offered in the last six months:

\begin{tabular}{|l|c|c|}
\hline Type of advice & $\begin{array}{c}\text { Number of nurses offering } \\
\text { advice }\end{array}$ & $\begin{array}{c}\text { Number of nurses unsure } \\
\text { about advice }\end{array}$ \\
\hline $\begin{array}{l}\text { 1 Review of physical activity } \\
\text { levels }\end{array}$ & \begin{tabular}{c}
$262\left(\begin{array}{c}96 \%) \text { out of } 274 \\
\text { responses }\end{array}\right.$ \\
\hline $\begin{array}{l}\text { 2. Ways of increasing } \\
\text { stamina }\end{array}$
\end{tabular} & $\begin{array}{c}270(94 \%) \text { out of } 287 \\
\text { responses }\end{array}$ \\
\hline 3. Brisk walking & $\begin{array}{c}256(95 \%) \text { out of } 271 \\
\text { responses }\end{array}$ & 17 unsure \\
\hline 4. Chair based exercises & $\begin{array}{c}175(72 \%) \text { out of } 244 \\
\text { respones }\end{array}$ & 69 unsure \\
\hline
\end{tabular}

Formatted: Space After: 0 pt, Line spacing: single

Table 3 Activity advice given by nurses who reported that they were exercising regularly each week $(n=181)$ and those

who reported that they were not exercising regularly each week $(n=215)$

\begin{tabular}{|c|c|c|}
\hline $\begin{array}{l}\text { Activity advice discussed in the last six } \\
\text { months }\end{array}$ & $\begin{array}{l}\text { Regular exercisers } \\
(\mathrm{n}=181)\end{array}$ & $\begin{array}{l}\text { Non-regular } \\
\text { exercisers } \\
(\mathrm{n}=215)\end{array}$ \\
\hline $\begin{array}{l}\text { 1. Review older people's current } \\
\text { activity levels }\end{array}$ & $\mathbf{1 3 3}(74 \%)$ & $\mathbf{1 2 4}(58 \%)$ \\
\hline $\begin{array}{l}\text { 2. Give out leaflets regarding activity } \\
\text { 3. Advise on activities that can } \\
\text { improve stamina }\end{array}$ & $\mathbf{8 2}(45 \%)$ & $\mathbf{7 8}(36 \%)$ \\
\hline $\begin{array}{l}\text { 4. Advise on activities that improve } \\
\text { muscle strength }\end{array}$ & $\mathbf{8 0}(44 \%)$ & $\mathbf{1 3 3}(62 \%)$ \\
\hline
\end{tabular}


2010:59:1 Activity Promotion for Community Dwelling Older People: A Survey of the Contribution, of Primary Care Nurses

\begin{tabular}{|c|c|c|}
\hline \begin{tabular}{l} 
5. $\begin{array}{l}\text { Refer to specialist exercise group } \\
\text { for older people }\end{array}$ \\
\hline 6. Refer to Falls Clinic
\end{tabular} & $\mathbf{5 8}(32 \%)$ & $\mathbf{4 7}(22 \%)$ \\
\hline $\begin{array}{l}\text { 7. Discuss health benefits of brisk } \\
\text { walking }\end{array}$ & $\mathbf{1 2 0}(63 \%)$ & $\mathbf{4 8}(22 \%)$ \\
\hline 8. Advise on chair based activities & $\mathbf{8 6}(48 \%)$ & $\mathbf{8 6}(40 \%)$ \\
\hline $\begin{array}{l}\text { 9. Recommend } 30 \text { minutes moderate } \\
\text { intensity activity five days a week }\end{array}$ & $\mathbf{6 6}(37 \%)$ & $\mathbf{5 6}(26 \%)$ \\
\hline
\end{tabular}

